\title{
The analysis and management of Wärtsilä engine control system-9520
}

\author{
Yuan Renmin \\ Maritime College, Shandong Jiaotong University, Weihai 264200, \\ Shandong, China \\ yrm0019@163.com
}

\begin{abstract}
.
In recent years, Wärtsilä RT-flex series electronic control diesel engine are increasingly applied to the ship.In order to make more safely and effectively to use, maintenance and management of the diesel engine, this paper mainly take 6RT-flex48T-D diesel engine as an example to introduce the RT-flex series electronic control diesel engine control system .
\end{abstract}

Keywords: RT - flex;Electronic control technology;Marine diesel engine; Control system; Use the management

\section{Introduction}

With the development of electronic control technology, control and monitoring of electronic control technology is more and more widely used in marine power plant.The RT-flex concept is based on the Wärtsilä common rail.Using electronic common rail control technology,the whole design of intelligent, modular. In the aspect of energy saving, environmental protection, reliability, security and flexibility than the previous models has been greatly improved, in line with the current energy efficiency control and emission standard.

\section{The composition of the control system}

RT-flex48T-D diesel engine is used in the WECS-9520 control system.The system adopts microcomputer control technology and fieldbus technology is mature, the realization of electronic control and monitoring of diesel engine. The redundant set are used in the module settings and distribution to ensure the reliability of bus. The composition and the connection of WECS-9520 control system shown in fig.1 and fig.2 . 


\section{The control system of Flex function unit}

As shown in Figure 1 the WECS-9520 control system of Flex junction box mainly comprises:a power box(E85), electrical rail box (E95.01 06), power distribution and external communication junction box(E90), local operation junction box(E25), cylinder pulse lubricating junction box(E41.01 06), the crank angle of the junction box(E96.1 and E96.2) and flexView software computer etc. In figure E95.01 05 only painted on the connection machine control function, 09 88 terminals with cylinder control function in E95.06.

\section{Control and safety alarm unit}

As shown in Figure 2 control and safety alarm connection box mainly comprises: a servo oil self-cleaning filter junction box(E92), piston cooling oil temperature monitoring terminal box(E111.1 3), piston cooling oil flow monitoring terminal box(E28, E28.01 06), engine speed detection and junction box(E20), super charger monitoring terminal box(E31), signal acquisition box(E110, E120.1 2, E12,E114.1), diesel engine safety junction box(E10).

\section{The function of the control system}

The main functions of the control system are: common rail pressure control, cylinder pulse lubricating control, fuel injection control, exhaust valve control, start valve control, crank angle detection etc.

\section{Common rail pressure control}

6RT-flex48T-D type diesel engine fuel supply unit has 2 fuel pump and the 2 servo oil pump, hanging in the output end of the machine, directly through the crankshaft gear drives. 


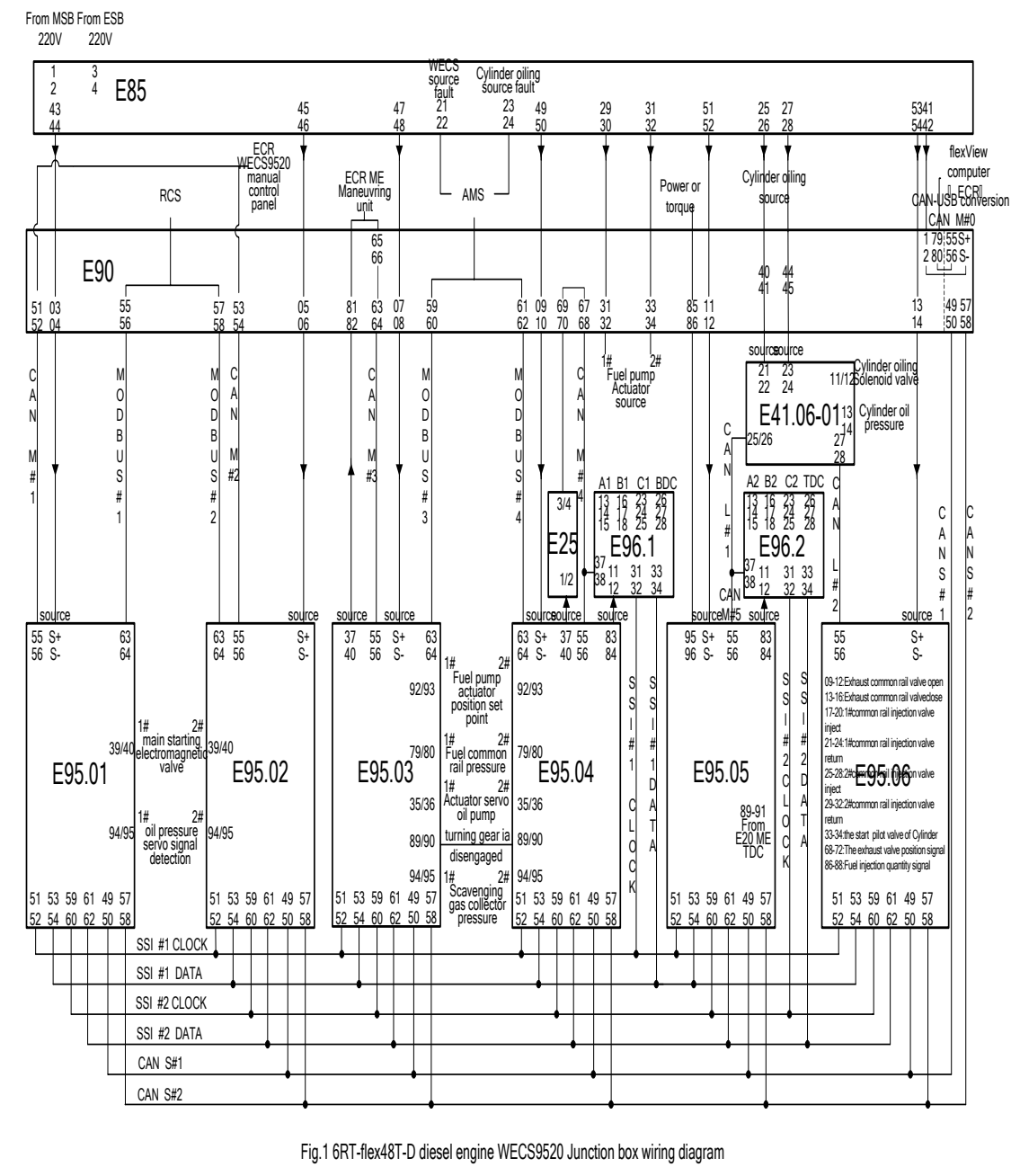




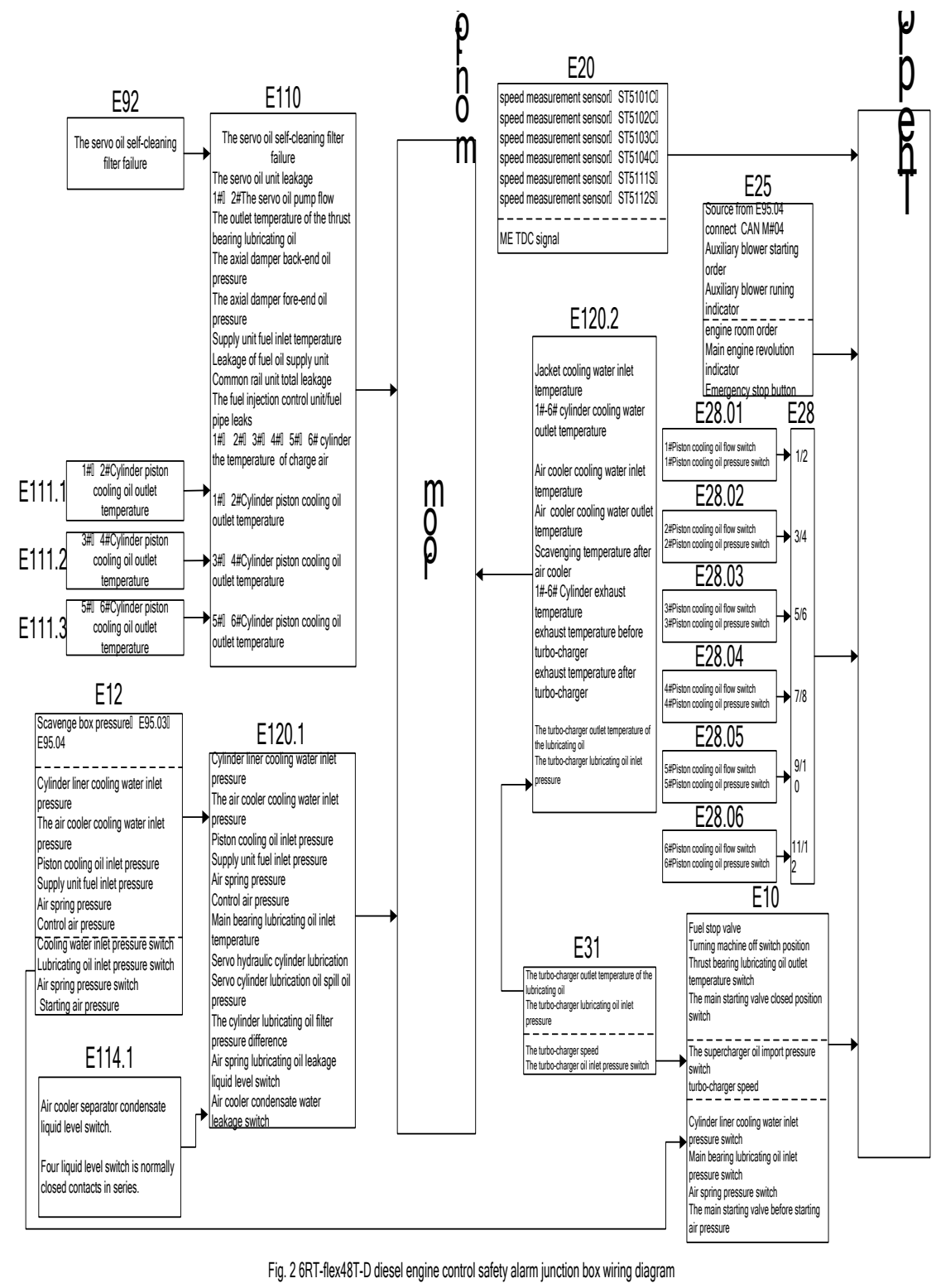

The common rail fuel pressure is changed with the diesel engine load has been shown in fig.3.WECS-9520 according to engine speed and fuel command, calculate the diesel engine load and calculated according to the load size to generate a pressure setpoint signal, by FCM-20 \#3 and \#4 module compared to two sets of common rail pressure sensor detects the pressure value and the external control system of fuel instruction to calculate fuel pump actuator 
adjustment instruction, by Woodward oil amount adjustment actuators pull the fuel pump rack.

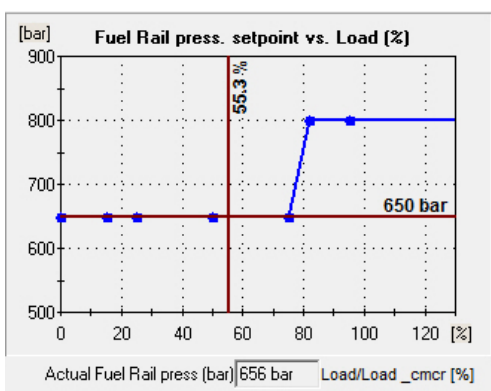

Fig. 3 the common rail fuel pressure set value

The control of servo oil pressure is also based on engine load changes, the set value signals produced by FCM-20 \#3 and \#4 respectively control pressure control mechanism of two servo pumps.Servo oil common rail pressure is feedback to FCM-20 \#1 and \#2 respectively detected by two pressure sensors.The common rail pressure was controlled between 80 190bar.

\section{Electronic cylinder pulse lubricating}

Cylinder lubrication system is by FCM-20 \#5 and \#6 according to the crank angle signal and the diesel engine load issued injection timing and fuel injection quantity control commands to the ALM-20\#1 \#6 control injector solenoid valve to perform the oiling action. And by the oil pressure sensor feedback oiling success.

\section{Fuel injection control}

Each cylinder FCM-20 Module according to the fuel command, crank angle signals and from the governing system received their timing calculation.Before the TDC, considering the VIT and FQS signals, calculate the precise injection angle, and the issue of fuel injection start and end of the instruction to the two common rail fuel valve to control fuel injection action ICU.

\section{Exhaust valve control}

The exhaust valve is opened by the servo hydraulic, and closed by an air spring pressure. Exhaust valve stem movement monitored by the position sensor, 
and give feedback to the control module.

\section{The start valve control}

The two main starting electromagnetic valve is respectively controled by FCM-20\#1 and \#2 according to the remote control system command sends control signal.

\section{The using and management}

The system control module

In the process of using the machine vibration is caused extremely easily loose system terminal, work pay attention to frequently check terminal. If the system is abnormal but after inspection found no cause of the malfunction, can be in this module off a few seconds, and then resupply. If normal, you can continue to use.If there are problems, replace the standby module.

\section{Fuel pump actuator}

In the daily maintenance, through the "Fuel Pump Actuators Position Test" command in the flexView user interface to test fuel pump actuator action, can test three positions: $0 \%, 50 \%, 100 \%$. In the diesel engine operation process, can be manually forcing one actuator mechanism, observation of another actuator whether automatic adjustment to the opposite direction, let go after two and will automatically return to the original position. If one actuator fault available special tools (distance piece) the fuel pump rack fixed position in $0,50 \%$ or $100 \%$, the fuel supply at this time is not adjustable, common rail pressure is adjusted by another, diesel engine load were restricted to $0 \sim 40 \%$, 20 80\%, 40 100\%.

\section{Common rail valve}

Common rail valve is a bistable uses high speed response of the 2 position 3 way valve. According to the rules given in the WECS-9520 directives, common railvalve coil to produce a high current pulse in a short period of time(50 60A), the spool moves about $0.3 \mathrm{~mm}$ displacement. Large current pulse and short spool displacement ensures a very short reaction time, so as to achieve precise control of fuel injection and exhaust valve. 


\section{Parameter adjustment}

The control flexibility of electronically controlled diesel engine lies in through flexView can be adjusted conveniently on the important control parameters, to improve the work performance.

"Base Feed Rate@CMCR”: the six cylinder rated load quantity of oil injection respectively adjusted, can use the "Set all" to modify the six cylinder unity. The adjusting range of feed rate is $0.6 \mathrm{~g} / \mathrm{kwh} 1.6 \mathrm{~g} / \mathrm{kwh}$, the value is out of range will be displayed in red. On the basis of actual feed rate with the diesel engine load and variable.

"Exvclosing Offset”:By changing a cylinder exhaust valve closing angle, to balance the cylinder compression pressure. The adjusting range of the parameters for $-3.0 \sim+3.0<0$, six cylinder compensation value average value should be between $-0.2 \sim+0.2<0$.

“InjBegin Offset”:By changing a cylinder fuel injection angle to regulate the detonation pressure of each cylinder, load balance. Fuel injection angle compensation is divided into two levels: $-0.5 \sim+0.5<0,-1.5 \sim+1.5<0$. The six cylinder compensation value average value should be between $-0.2 \sim+0.2<0$.

\section{Summary}

Now the new ship in the host application more and more electronic control diesel engine, electronic control diesel engine technology is becoming more and more perfect. The engineers to learn and understand the electronic control technology for diesel engine. Believe that with the continuous improvement of this series diesel engine knowledge and the accumulation of management experience, the electronically controlled diesel engine can fully play the advantages.

\section{Reference}

[1] Wärtsilä Switzerland Ltd.Wärtsilä RT-flex48T-D Operating Manual [M]. 2012 .

[2] Wärtsilä Switzerland Ltd.Wärtsilä RT-flex48T-D Maintenance Manual [M]. 
2012.

[3] Wärtsilä Switzerland Ltd. Operator flexView Manual Revision 3.0 [M].2012.

[4] Wärtsilä Switzerland Ltd, RT-flex Training:Function of the CLU-4 Pulse Feed Cylinder Lubrication System[M].2012.11

[5] Wärtsilä Land \& Sea Academy .RT-flex Training:RT-flex Bus Systems 